\title{
Loss of Notch signalling induced by DII4 causes arterial calibre reduction by increasing endothelial cell response to angiogenic stimuli
}

\author{
Rui Benedito ${ }^{1,2,7}$, Alexandre Trindade ${ }^{1,2}$, Masanori Hirashima ${ }^{3}$, \\ Domingos Henrique ${ }^{4}$, Luis Lopes da Costa ${ }^{1}$, Janet Rossant ${ }^{5}$, Parkash S Gill ${ }^{6}$ \\ and António Duarte*1,2
}

Address: ${ }^{1}$ Centro Interdisciplinar de Investigação em Sanidade Animal, Faculdade de Medicina Veterinária, Technical University of Lisbon, Lisboa, Portugal, ${ }^{2}$ Instituto Gulbenkian de Ciência, Oeiras, Portugal, ${ }^{3}$ Sakaguchi Laboratory of Developmental Biology, School of Medicine, Keio University, Tokyo, Japan, ${ }^{4}$ Instituto de Medicina Molecular, Faculdade de Medicina da Universidade de Lisboa, Lisboa, Portugal, ${ }^{5}$ Department of Pathology, University of Southern California Keck School of Medicine, Los Angeles, CA, USA, ${ }^{6}$ Program for Developmental Biology, Hospital for Sick Children, Toronto, Canada and ${ }^{7}$ Max Planck Institute for Molecular Biomedicine, Muenster, Germany

Email: Rui Benedito - Rui.Benedito@cancer.org.uk; Alexandre Trindade - alexandret@netcabo.pt;

Masanori Hirashima - mhirashi@sc.itc.keio.ac.jp; Domingos Henrique - henrique@fm.ul.pt; Luis Lopes da Costa - lcosta@fmv.utl.pt;

Janet Rossant - janet.rossant@sickkids.ca; Parkash S Gill - parkashg@usc.edu; António Duarte* - aduarte@fmv.utl.pt

* Corresponding author

Published: 16 December 2008

BMC Developmental Biology 2008, 8:1 I7 doi:10.1 186/147I-213X-8-1 I7

This article is available from: http://www.biomedcentral.com/I47I-2I3X/8/II7

(C) 2008 Benedito et al; licensee BioMed Central Ltd.

This is an Open Access article distributed under the terms of the Creative Commons Attribution License (http://creativecommons.org/licenses/by/2.0), which permits unrestricted use, distribution, and reproduction in any medium, provided the original work is properly cited.

\begin{abstract}
Background: In the vascular system, Notch receptors and ligands are expressed mainly on arteries, with Delta-like 4 (DII4) being the only ligand known to be expressed early during the development of arterial endothelial cells and capillaries. DIl4 null embryos die very early in development with severely reduced arterial calibre and lumen and loss of arterial cell identity.

Results: The current detailed analysis of these mutants shows that the arterial defect precedes the initiation of blood flow and that the arterial DII4-- endothelial cells proliferate and migrate more actively. DII4-- mutants reveal a defective basement membrane around the forming aorta and increased endothelial cell migration from the dorsal aorta to peripheral regions, which constitute the main causes of arterial lumen reduction in these embryos. The increased proliferation and migration of DII4-/- endothelial cells was found to coincide with increased expression of the receptors VEGFR-2 and Robo4 and with downregulation of the TGF- $\beta$ accessory receptor Endoglin.
\end{abstract}

Conclusion: Together, these results strongly suggest that Notch signalling can increase arterial stability and calibre by decreasing the response of arterial endothelial cells to local gradients of proangiogenic factors like VEGF.

\section{Background}

The initial steps of embryonic blood vessel formation (vasculogenesis) involve differentiation and aggregation of mesodermal-derived endothelial precursors (angiob- lasts) to generate the primary vascular plexus. Blood vessels then grow and remodel into a mature network of hierarchically organized vessels, in a process designated as angiogenesis. During this remodelling, endothelial vessels 
differentiate into arteries and veins, grow, sprout, split and fuse according to a combination of autocrine signalling and cues provided by other tissues of the embryo [1].

The formation of the initial vascular plexus is highly dependent on vascular endothelial growth factor (VEGFA) and its receptors, VEGFR-1 and VEGFR-2, since mouse embryos lacking these genes display very early vascular defects and die between 8.5-9.5 dpc [2-4]. Notably, VEGF haploinsufficiency causes embryonic lethality. VEGFR-2 is thought to be the major mediator of the VEGF signalling since VEGFR-2\% embryos fail to form blood islands or organized blood vessels [3], whereas VEGFR-1\% embryos form blood vessels with an excess of endothelial and haemangioblast progenitors $[4,5]$. Furthermore, deletion of the VEGFR-1 tyrosine kinase domain does not affect vascular development [6]. In some contexts VEGFR-1 seems to work as a biological sink to VEGF, antagonizing VEGFR-2 mediated signalling [7,8]. Through activation of VEGFR-2, VEGF induces phosphorylation of several proteins which in turn regulate endothelial cell permeability, proliferation, migration and survival. During later vessel remodelling, other ligands become increasingly important and the disruption of the signalling induced by angiopoietins, ephrins, TGF- $\beta$, slits or netrins causes specific vascular defects that often leads to early embryonic death $[9,10]$.

The Notch pathway is also involved in the regulation of vascular development as the single gene deletion of Notch1 or combined deletion of Notch1 and Notch4 results in severe defects in early arterial development [11]. The Notch receptors can bind five known ligands from the Delta (Dll1, Dll3 and Dll4) and Jagged (Jagged1 and Jagged2) families. The Dll4 ligand is the only canonical Notch ligand strongly expressed in arterial endothelial cells at early stages of development $[11,12]$. Beside VEGF, Dll4 is the only other known vascular-related haploinsufficient lethal gene, indicating how critical its dosage levels are for vascular development [13-15]. We have previously shown that the majority of the Dll4+/- embryos die at 10.5 $\mathrm{dpc}$ in the CD1 genetic background, whereas all the Dll4-1 - embryos die at $9.5 \mathrm{dpc}$ with severely reduced dorsal aortae. Furthermore, Dll4 \% aortic endothelial cells lose the expression of the arterial-specific genes Efnb2 and Gja4 (Cx37), and ectopically express the vein marker Ephb4, one of the receptors for the arterial ephrinB2 ligand [15].

In order to understand the cause of this arterial calibre and lumen reduction, a stepwise analysis of the early vascular development of Dll4 $\%$ embryos was carried out.

\section{Methods \\ Mice}

All procedures complied with the standards for care and use of animal subjects as stated in the Guide for the Care and Use of Laboratory Animals (Institute of Laboratory Animal Resources, National Academy of Sciences of the U.S.A.) and were approved by the institutional committee for the ethical use of laboratory animals of the Faculdade Medicina Veterinaria (project POCTI 48677). Embryos were obtained by the intercross of Dll4+/- mice in the CD1 genetic background as described previously [15]. These heterozygous mice were kept in the CD1 genetic background due to the higher lethal haploinsufficiency in the other tested genetic backgrounds (almost 100\%). The embryonic age was initially determined by the date of the formation of the copulation plug and confirmed by the number of somites.

\section{$X$-Gal staining, immunofluorescence and in situ hybridization}

Whole-mount immunohistochemistry and X-gal staining were carried out by standard techniques [16]. For sections, after fixation in 4\% paraformaldehyde (PFA), embryos were cryoprotected in 15\% sucrose, embedded in $7.5 \%$ gelatine and cryosectioned at $12 \mu \mathrm{m}$. Antibodies against PECAM-1 (Pharmingen), $\alpha$ SMA (Sigma), SM22 $\alpha$ (Abcam), $\beta$-catenin (Sigma), Fibronectin (Sigma), Endoglin (Pharmingen), Laminin (Abcam) and CollagenIV (Chemicon) were used as primary antibodies and speciesspecific conjugated to Alexa Fluor (Molecular Probes) were used as secondary antibodies.

In situ hybridization of cryostat sections with digoxigenin labelled riboprobes Dll4 (full-length); Flk1 [17]; Flt1 [4]; Notch1 (a 2168 bp BamHI-EcoRV fragment of the NM_008714 cDNA clone, starting at nucleotide 4205 and ending at nucleotide 6373); Hey1 [18], VEGFA [19], was essentially done as previously described [20]. After overnight incubation with anti-Dig-AP (1:2000, Roche) the signal was developed with Fast Red solution (Roche) or BM purple (Roche). The double in situ hybridization was done with the Dll4 riboprobe labelled with fluorescein and the Notch1 with digoxigenin. For the amplification of the Dll4 signal was used the anti-Fluo-POD (1:100, Roche) and the FITC-tyramide from the TSA-Plus Fluorescein System (Perkin Elmer). The Notch1 signal was developed after the Dll4 signal as for the single in situ hybridizations. Fluorescence images were acquired on a Leica DM5000B microscope (sections) or an Olympus SZX12 stereomicroscope (wholemount). Confocal images were acquired using a Leica Spectral AOBS microscope. All the images were processed on Adobe Photoshop 9.0.

\section{BrdU and TUNEL labelling}

BrdU labelling was achieved by a 2 hour BrdU pulse (100 ug BrdU/g body weight, intraperitoneally) before fixation in $4 \%$ PFA. Cryosections from the fixed embryos were treated in $50 \%$ formamide $/ 1 \times \mathrm{SSC}, \mathrm{pH}=7$ for 1 hour at $65^{\circ} \mathrm{C}$ and $\mathrm{HCl}(7.5 \%)$ for 30 minutes at $37^{\circ} \mathrm{C}$ and incubated overnight with mouse anti-BRDU (1:1000, Sigma). 
To visualize the nucleus a15 minute incubation in DAPI solution followed by a brief fixation in $4 \%$ PFA was performed before the DNA denaturation. Endothelial antiPECAM-1 immunostaining was performed also before the BrdU immunostaining. In this experiment we used consecutive cryosections from all the anterior-middle region of the embryos ( 2 embryos from each genotype). From each cryosection a 3 channel picture was taken and used to score the number of total and proliferating aortic endothelial cells.

To detect apoptotic endothelial cells on cryosections, antiPECAM-1 and DAPI staining after TUNEL labelling and staining with the fluorescein in situ cell death detection it (Roche) was performed. Cell counting was carried out as described for the BrdU staining.

\section{Quantitative PCR}

Total RNA was extracted from whole embryos, after removal of the yolk sac, with the RNeasy Mini Kit (Qiagen). cDNA synthesis was done using the Superscript III First Strand Synthesis kit (Invitrogen). In two different experiments embryos were obtained from two different litters ( $\mathrm{n}=4$ for each genotype). In each experiment, for each analysed gene, 6 separate real time PCR (RT-PCR) reactions were carried out, in triplicates, using SYBR Green Mixes and ABI PRISM 7300 (Applied Biosystems). Gene expression was normalised to -actin. Used Primer sequences are as follows: -actin 5'-TGTTACCAACTGGGACGACA-3'and 5'-GGGGTGTTGAAGGTCTCAAA3';VEGFR2 5'-GGCGGTGGTGACAGTATCTT-3' and 5'GAGGCGATGAATGGTGATCT-3' VEGFR1 5'-GACCCTCTTTTGGCTCCTTC-3' and 5'-CAGTCTCTCCCGTGCAAACT-3' ; VEGFA 5'-GGAGAGCAGAAGTCCCATGA3' and 5'-ACACAGGACGGCTTGAAGAT-3'; Hey1 5-CACCTGAAAATGCTGCACAC-3' and 5'-ATGCTCAGATAACGGGCAAC-3'; Hey2 5'-TGCCAAGTTAGAAAAGGCTGA-3' and 5'-CACTCTCGGAATCCAATGCT-3'; Cx37 5'-ACGGTCGTCCCCTCTACCT-3' and 5'-GTCGAGTGTTCCTGGACCTG-3'; Endoglin 5'-CACACCTCCCAAGGACACAT3' and 5'-TGGAGTCCCAGAAAGTCAGG-3'; Robo4 5'CGAGGACGCCATTCTAAAAC-3' and 5'-CCAATCCCAGC CGACTACTA-3' and PECAM 5'-GTGGTCATCGCCACCTTAAT-3' and 5'-GGCTTCCACACTA GGCTCAG-3'.

\section{Results}

Reduced arterial calibre in DII4-/- embryos is determined before the onset of blood flow and is not caused by defects in angioblast differentiation

The Dll4 gene starts to be expressed in the embryo at the 2-somite stage in the endothelium of the developing heart and dorsal aortae [15]. As the development of the dorsal aortae is coincident with heart development and the initiation of blood flow, we asked if the early arterial calibre and lumen reduction seen in the Dll4-/-embryos could be related to impaired haemodynamic forces, which are known to influence arterial identity and remodelling [21]. Confocal imaging of the dorsal aortae of 8-somite stage (ss) embryos shows that in Dll4\% embryos the arterial calibre and lumen is already significantly reduced before the initiation of heart beat and blood flow, which begins around 10-11 ss (Fig. 1A, B). Together with previous observations [22], these results suggest that the initial regulation of blood vessel size is an intrinsic property of early endothelial cells.

The reduction of the arterial calibre could arise from either defects in the maturation of the dorsal aorta once formed or from abnormal differentiation and impaired migration of angioblasts from the lateral plate mesoderm to the midline of the embryo. Angioblasts are endothelial progenitors and express high levels of VEGFR-2 and no detectable levels of PECAM-1 [22]. In situ hybridization with probes for the Notch1 and Dll4 mRNAs shows that Dll4 is not expressed in cells from the lateral plate mesoderm, where angioblasts (VEGFR-2+/PECAM-) are located (Fig. 1C, D, E and $1 \mathrm{~F}$ ), and only becomes expressed after initiation of aorta formation. This indicates that the reduction of the arterial calibre observed in the Dll4 $\%$ embryos is not caused by defects in early angioblast differentiation or migration to the midline, since Dll4 is only expressed at the aortic endothelium at this stage.

\section{DIl4-/- arterial endothelial cells display abnormal morphology and a defective basement membrane}

To study the nature of Dll4\% endothelial cell phnotype we analysed endothelial morphology and extracellular matrix integrity in embryos with $8-11$ somites, the stage immediately before the onset of circulation and when the phenotype starts to become more pronounced. The analysis of transverse sections labelled with the endothelial marker PECAM-1 revealed that the Dll4 $\%$ aortic endothelial cells, in the anterior and middle region of the embryo, are frequently more aggregated and do not acquire a spindle-like shape (Fig. 2A, B and 2C). The majority of these cells display a rounder morphology which is characteristic of incompletely differentiated or loosely attached endothelial cells. Interestingly, fibronectin, laminin and collagenIV immunostaining further revealed that these cells have a severely defective basement membrane in both the anterior and posterior (presomitic) dorsal aortae (Fig. 2G-T). Whereas in a normal developing dorsal aorta there is accumulation of a thick layer of surrounding fibronectin, in the Dll4\% embryos the endothelial matrix is very irregular and some of the arterial endothelial cells are not in direct contact with it. These defects occur both in the anterior and presomitic domains of the dorsal aortae, whereas the arterial calibre reduction occurs only in the anterior domain. This suggests that the defects observed in basement membrane integrity are not suffi- 

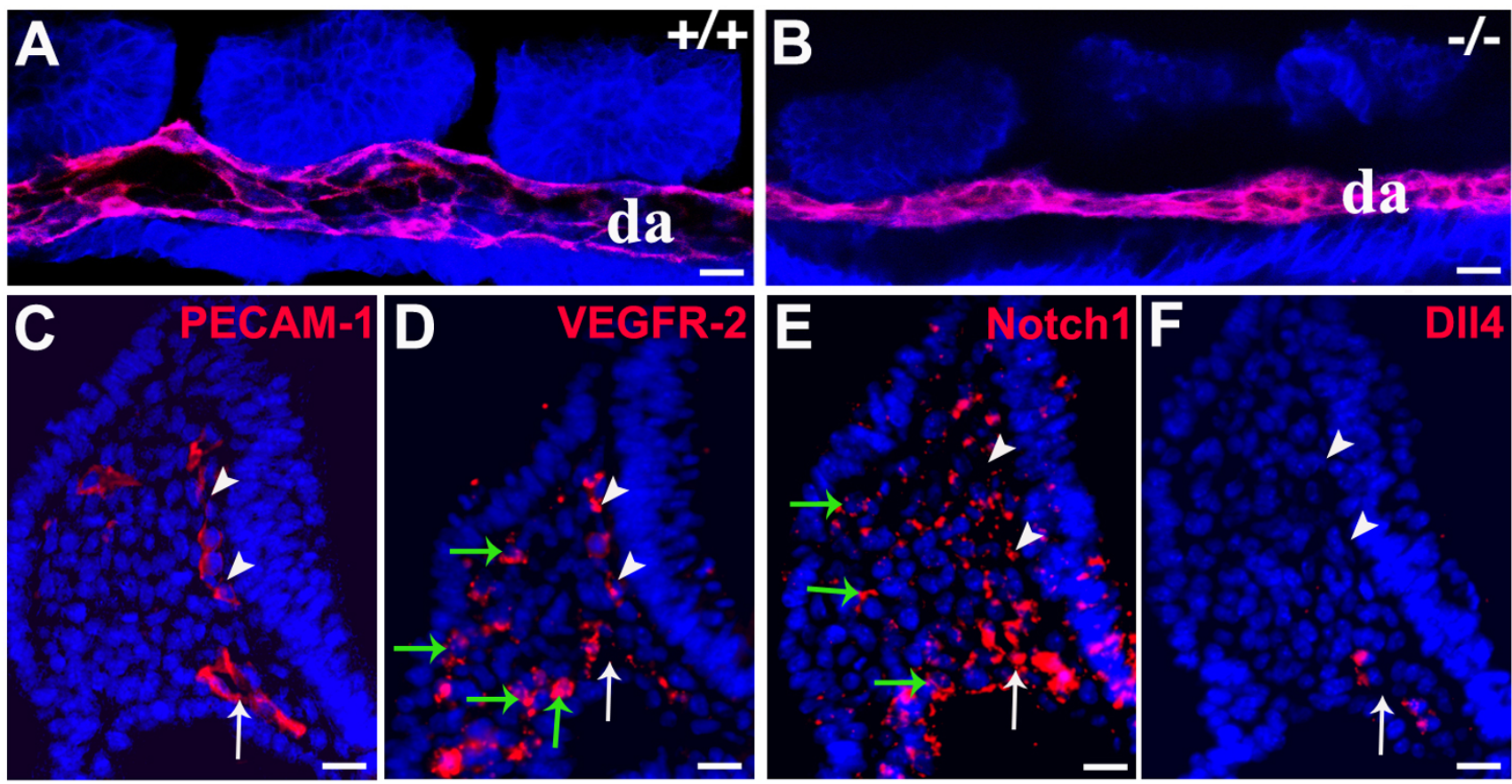

Figure I

The dorsal aortae calibre and lumen reduction in the D/I4-/- embryos is not caused by blood flow or angioblast defects. $(A, B)$ Confocal imaging analysis of 8 ss D/l4 $4^{+/+}$and D/l4-/- embryos showing in red the dorsal aortae (da) endothelial cells (labelled with anti-PECAM-I) and in blue all the other cells from the adjacent tissues (labelled with anti- $\beta$-catenin). (C-F) Anti-PECAM-I or fluorescent in situ hybridization on consecutive cryosections from a D/l4 $4^{+/+} 8$ ss embryo, showing that VEGFR-2 and Notch I are expressed in the endothelial cells (PECAM-I+) and in the mesoderm cells from the lateral plate (green arrows), where angioblasts arise. The DIl4 mRNA is not detected on the angioblasts or on the primordial anterior cardinal vein (white arrowheads) but only on aortic endothelial cells (white arrows). (Scale Bars: I5 $\mu \mathrm{m}$ ).

cient to explain the reduction in the arterial calibre seen in the Dll4\%-embryos.

\section{DII4-/- aortic defects precede smooth muscle development} Besides the formation of the basement membrane, another biological process that confers stability and cohesion to the developing arteries is the recruitment of pericytes and smooth muscle cells. Immunostaining for alpha smooth muscle actin ( $\alpha$ SMA) (Fig. 2D) and in situ hybridization for $P d g f r b$ (data not shown) on $\mathrm{Dll4}^{+/+}$embryonic sections at this developmental stage, showed that there is virtually no differentiated smooth muscle cells or pericytes associated with the endothelium of these primordial arteries. To further investigate a possible function of Dll4 in arterial smooth muscle cell recruitment we did imunostaining for Sm22 $\alpha$ a gene highly expressed by neural crest derived smooth muscle cells and progenitors. We detected Sm $22 \alpha$ in several cells surrounding the control and mutant aortic endothelium but just some $\operatorname{Sm} 22 \alpha$ positive cells were found immediately adjacent and adherent to the aortic endothelial cells (Fig. 2E, F). Most of the mural cells $\operatorname{Sm} 22 \alpha+$ in contact with the endothelial cells showed a round shape and were not completely attached to it. In fact we detected less Sm22 $\alpha+$ cells in contact with the Dll4/- aortas, although this can be related to the reduced arterial calibre and available endothelial cell surface. We also analysed Sm $22 \alpha$ staining in the pre-somitic region, where Dll4 $\%$ and control aortae have a similar calibre, but at this level we could not observe Sm $22 \alpha+$ cells surrounding the aorta of either control or mutant embryos. These results suggest that the arterial phenotypic consequences of Dll4 loss of function precede the existence of fully differentiated supporting cells in the arteries.

\section{Loss of the Notch ligand DII4 increases endothelial cell proliferation and migration}

To further characterize the Dll4\%-endothelial cell behaviour we analysed the in vivo proliferation and migration of endothelial cells. To detect the primary defect the analysis of the aortic endothelial cell number and proliferation rate was done with Dll4+/+ and Dll4\% embryos with 8 somites. Each embryo was serially sectioned and immunostained for PECAM-1 and BrdU. At this early stage of development there are $28 \%$ less endothelial cells in the Dll4 $\%$ aortae compared to the control dorsal aortae (Fig. $3 \mathrm{~A})$, and as development proceeds this difference 

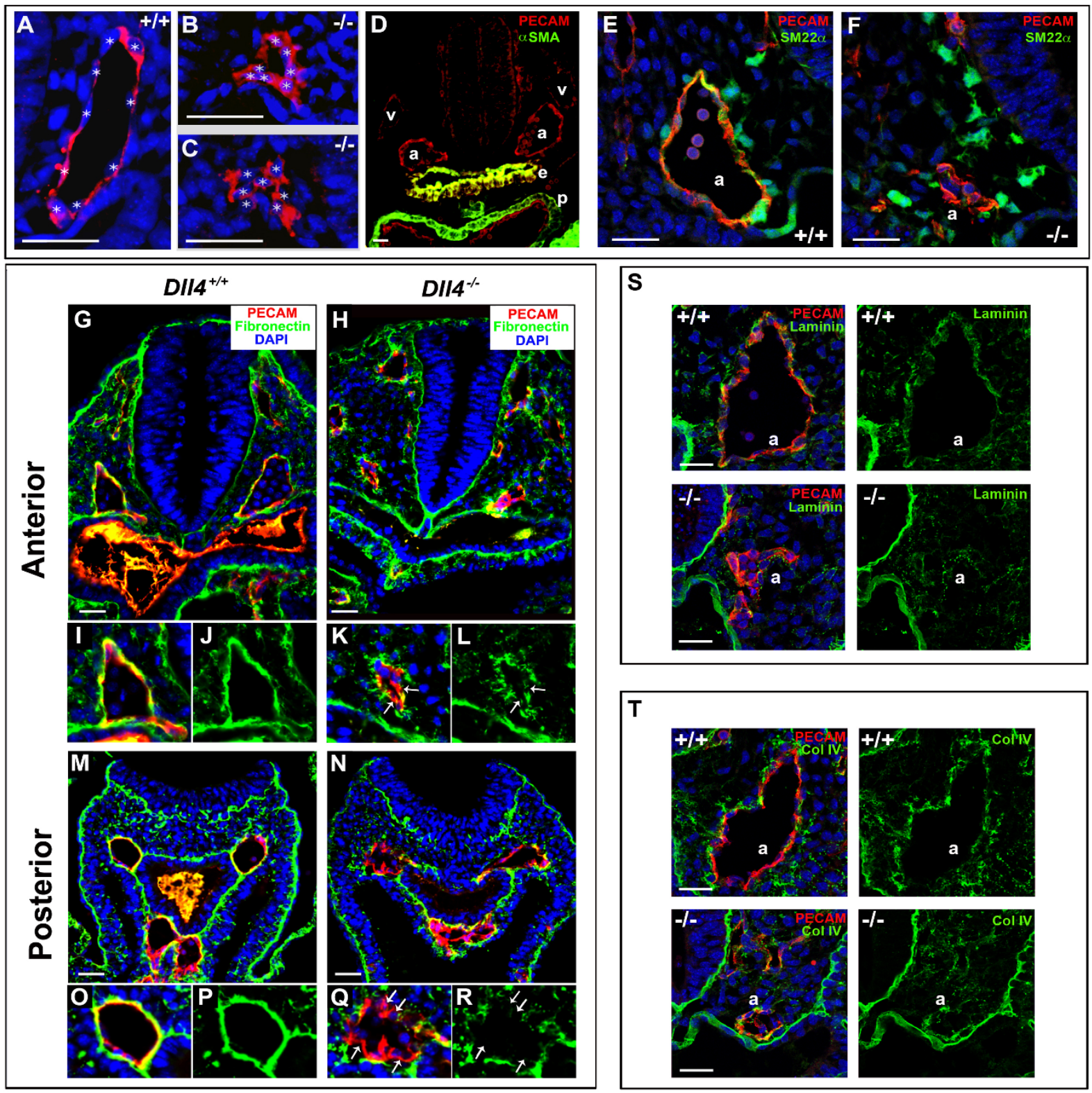

Figure 2

The DII4-- arterial endothelial cells have an abnormal morphology, become more aggregated and display a defective basement membrane. (A-C) Anti-PECAM-I staining of $8 \mathrm{ss}$ embryo cryosections showing the morphology of $\mathrm{D} \| 14^{+/+}$and DII4-/- dorsal aortae endothelial cells. The white stars label the DAPI stained endothelial nuclei. DII4-/- endothelial cells are more aggregated and fail to develop a stretched spindle-like form which leads to a reduced (B) or absent aortic lumen (C). (D) Anti-PECAM-I (red) and anti- $\alpha$ SMA (green) staining of 16 ss cryosection of a Dll4 $4^{+/+}$embryo showing the absence of arterial (a) and venous (v) endothelium associated smooth muscle cells. Note the strong aSMA staining in the endoderm (e) and pericardium (P). (E, F) Both control and mutant dorsal aortae (a) are surrounded by neural crest derived smooth muscle cell progenitors with high amounts of Sm22 $\alpha$ protein (in green). (G-R) Anti-PECAM-I (red), anti-fibronectin (green) and DAPI (blue) staining of cryosections from the anterior (G-L) and posterior (M-R) region of II ss DII4+/+ and DII4-l- embryos. Figures $\mathbf{I}-\mathbf{L}$ and $\mathbf{O}-\mathbf{R}$ are close ups of the upper left dorsal aortae and show the defective basement membrane (green) in both the anterior and posterior regions of the DII/-I-aortae. In the mutants many endothelial cells are not in direct contact with the underlying, fibronectin-rich, extracelular matrix (arrows). (S, T) At this stage of development the aortic (a) basement membrane is relatively poor in laminin $(\mathrm{S}$, control) and collagenIV $(\mathrm{T}$, control) when compared with fibronectin $(\mathrm{V}$ and $\mathrm{P})$. The reduced DII4-/- dorsal aortae have even less and more irregular laminin and collagenIV coverage. (Scale Bars: $30 \mu \mathrm{m}$ ). 
becomes more pronounced (data not shown). Unexpectedly, however, the proliferation rate of aortic Dll4-/ endothelial cells is almost two-fold higher (Fig. 3B, D). This apparent contradiction could be explained by either increased apoptosis or increased outward migration of the aortic Dll4- endothelial cells. To test the first hypothesis, we performed TUNEL analysis, which showed that although there is an increase of endothelial cell apoptosis, its rate is too low to counterbalance the increase in endothelial cell proliferation (Fig. 3C).

The sequential analysis of the intersomitic vessel development from 10 to 14 ss embryos showed that Dll4\% aortic endothelial cells migrate earlier and faster through the intersomitic space and accumulate in excessive numbers in the region of dorsal anastomotic vessel formation (Fig. 3E-J). Every time a somite forms in the posterior region a new gradient of angiogenic factors is established within the newly formed intersomitic space boundaries, which attracts the endothelial cells. Therefore, the migration of Dll4 \%-endothelial cells is more advanced in the first than in the last somites. Consequently, the mutant dorsal aortae calibre is also much more reduced in the anterior somites and increases gradually until the most posterior somites and presomitic mesoderm, where its calibre is normal (Fig. 3J). To further investigate how these embryonic tissues regulate this gradual endothelial cell migration, we performed in situ hybridization with a probe to the VEGF-A mRNA on embryonic sections. In the anterior and middle regions of the embryo, the neural tube and the endoderm express high levels of VEGF-A, but in the presomitic mesoderm, where dorsal aortae do not sprout, VEGF-A mRNA was only detected in the endoderm, close to the dorsal aortae (Fig. 3M, N). This indicates that the neural tube, and not only the somites, can be a regulator of intersomitic vessel sprouting and dorsal growth. The results suggest that in the absence of angiogenic gradients secreted by the somites and the neural tube (as in the presomitic mesoderm), the Dll4\% endothelial cells remain associated with the dorsal aortae and form a normal arterial lumen, even though they have a defective basement membrane as described above.

This increased migration of arterial endothelial cells also occurs towards the region of the developing limb bud, where an accumulation of Dll4-lacZ + endothelial cells can be seen (Fig. 3I, J). In the anterior asomitic region of the embryo there is also an increased accumulation of endothelial cells in a dorsal region where the primordial anterior cardinal vein arises and develops. Confocal analysis shows increased but restricted sprouting of endothelial cells from the dorsal aortae, since we did not observe further extension and somite invasion of these sprouts (Fig. 3K, L). Altogether, these results suggest that the dorsal aortae calibre and lumen reduction seen in the Dll4-/- embryos is mainly caused by the increased outward migration of the endothelial cells from the central dorsal aortae to peripheral regions of the embryo. As Dll4 is not expressed in non-vascular tissues at these stages of development, the observed phenotype suggests a specific increase of endothelial cell response to normal angiogenic attractant gradients produced by surrounding tissues.

\section{Venous localization of the DII4-/- "arterial" endothelial cells}

One of the distinguishable features of mammalian arterial and venous early development is that the venous angioblasts migrate and form the initial anterior cardinal vein in a dorsal position close to the neural tube, whereas arterial angioblasts form the dorsal aortae ventrally and close to the endoderm. Little is known about the molecular mechanisms that regulate this early segregation of arterial and venous lineages. In the Dll4 $\%$ embryos we can follow the migration of arterial endothelial cells by analysis of lacZ expression, because the $\beta$-galactosidase protein is very stable. In the anterior, asomitic region, of the Dll4 \% embryos abnormal migration of "arterial" endothelial cells to the region where the primordial anterior cardinal veins form was very frequently observed (Fig. 4A-D). This migration is frequently associated with arterial-venous fusions (Fig. $4 \mathrm{G}, \mathrm{H}$ ) and an increase of the pool of venous endothelial cells. At later stages, in the middle (somitic) region of the embryo, almost all arterial endothelial cells localize dorso-laterally to the neural tube and not ventrally as in the wild-type embryo (Fig. 4E, F). The observed migration and delocalization of the arterial Dll4\% endothelial cells to the dorsal and venous region can be related with the incomplete differentiation of the "arterial" endothelial cells and abnormal increased responsiveness to the angiogenic factors produced by the neural tube. Alternatively, these cells can be less sensitive to the existing repulsive factors. We previously showed that these Dll4-/- "arterial" endothelial cells express the vein marker Ephb4 and fail to express detectable levels of the arterial marker Efnb2. So these uncommitted "arterial" endothelial cells may respond to the distribution of the gradients like the venous angioblasts or endothelial cells.

\section{Arterial DII4--- endothelial cells express more VEGFR-2 and Robo4 and less Endoglin}

To better understand the molecular mechanisms that can be at the origin of this abnormal behaviour of the Dll4 $\%$ endothelial cells we performed quantitative RT-PCR for several known early angiogenesis regulator genes. The analysis was done with total RNA extracted from 11 ss embryos. This stage was selected because the effects of the mutation and defective blood flow in remodelling are just starting and the expression of known arterial markers is increased comparative to earlier stages. The use of total RNA from the embryos limited our ability to determine 

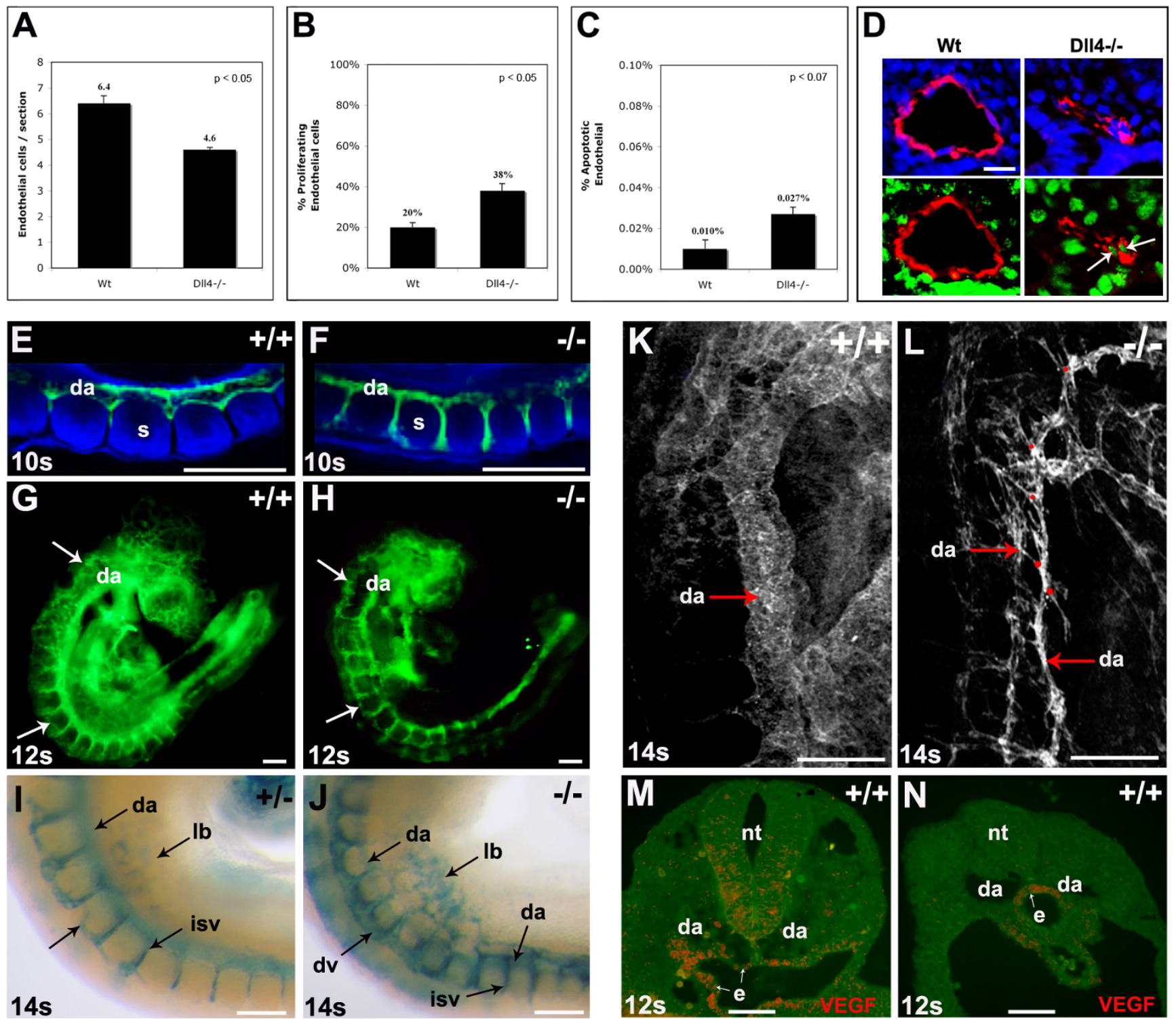

\section{Figure 3}

Increased proliferation, sprouting and migration of DII4-/- arterial endothelial cells. (A-C) Quantification of the endothelial cell number per aortic section (A), percentage of proliferating endothelial cells (B), and percentage of apoptotic endothelial cells (C) in the aortae of 8ss Wt and DII4-/- embryos ( $n=2$ for each genotype, 30 sections per embryo). (D) Representative images of the sections used for quantification. Endothelial cells are shown in red (anti-PECAM-I), nuclei in blue (DAPI) and proliferating cells in green (anti-BRDU). The proliferating endothelial cells are also indicated (arrows). (E-J) Whole-mount embryos labelled with anti-PECAM-I (E-H, green) or X-gal (I, J) showing the increased migration of intersomitic vessel (isv) DII4-/- endothelial cells. (E, F) Confocal imaging of the somitic region of IOss embryos showing that in DII4-/- embryos (F) the aortae endothelial cells invade the intersomitic space earlier and migrate extensively, causing the calibre reduction of the dorsal aortae (da). (G, H) At I2ss the endothelial cells start to accumulate in the dorsal domain (arrows) of the DII4-/embryos. (I, J) The X-gal staining of I4ss embryos shows the accumulation of endothelial cells (blue) in the dorsal region of the DIII-/-first anterior-middle somites (J), forming a large dorsal vessel (dv). The DII4-/- cells also migrate extensively to the primordial limb buds (Ib). (K, L) Confocal imaging of I 4ss wholemount embryos labelled with anti-PECAM-I. The DII4-I- dorsal aortae (da) are thinner and show extensive sprouting (red dots). (M, N) In situ hybridization for VEGF mRNA on cryosections of a 12 ss embryo shows that in the anterior region (M), VEGF is expressed by both the neural tube (nt) and endoderm (e) cells, but in the posterior (pre-somitic) region $(\mathrm{N})$ is only expressed by the endoderm cells. Error bars indicate s.e.m. (Scale Bars: $\mathrm{D}$, $25 \mathrm{~mm} ; \mathrm{E}-J, \mathrm{I} 50 \mathrm{~mm} ; \mathrm{K}-\mathrm{N}, 100 \mu \mathrm{m})$. 
the expression changes specifically within endothelial cells. The results show a $41 \%$ increase in the VEGFR-2 expression level in the Dll4\% embryos and no significant variation of VEGFR-1 expression. In addition, Robo4 was upregulated by $56 \%$ and Endoglin downregulated by $41 \%$ (Fig. 5A). As the Dll4 gene is only expressed in the embryonic arteries, whereas VEGFR-2, Robo4 and Endoglin are also expressed in angioblasts and venous endothelial cells [17,23-25], this difference could be even more significant if RNA from only arterial endothelial cells had been used. The PECAM-1 expression level was used as a control of the endothelial fraction in the samples and Cx37, a known arterial specific marker, was used as a control of arterial differentiation. Its expression is reduced almost four-fold in the Dll4 \% embryos. As expected, the canonical Notch effectors Hey 1 and Hey 2 are also downregulated in the mutants. The reduction in the expression level is probably not higher because these two genes are also expressed in other non-endothelial tissues. By in situ hybridization on Dll4 $\%$ sections we did not detect Hey 1 mRNA in the arterial endothelial cells (Fig. 6I). On the other hand, the levels of expression of Tie-2 and VE-cadherin genes showed no significant differences between wild-type and Dll4\%embryos (data not shown).

Since these qRT-PCR results represent differences in whole embryo expression levels, in situ hybridization with a probe for the VEGFR-2 mRNA on wild-type and Dll4embryos was carried out. In wild-type and heterozygous embryos the VEGFR-2 gene was found to be more strongly expressed in the venous endothelium than in the arterial endothelial cells, where the Dll4 gene is strongly expressed (Fig. 5B, C). Interestingly, in the Dll4 $\%$ embryos the expression level of VEGFR-2 in arterial endothelial cells is higher and similar to its expression in veins (Fig. 5D). In situ hybridization for VEGFR-1 and imunostaining for endoglin was carried out without detection of any clear difference between Dll4+/+ and Dll4/- aortae. Together these results show that, in relation to their wild-type counterparts, Dll4- endothelial cells express more VEGFR-2 and Robo4, both of which are involved in the regulation of endothelial cell proliferation and migration [23,26-28] and express less the TGF- $\beta$ accessory receptor endoglin, which when ablated in vitro increases endothelial cell proliferation [29] and in vivo decreases arterial stability and smooth muscle cell recruitment [30].

\section{Notch-DIl4 signalling in developing arteries does not occur through lateral inhibition}

Notch signalling, in most cellular processes studied so far, functions through lateral inhibition, where a Notch signal receiving cell upregulates the expression of the Hes/Hey genes and downregulates the expression of Delta. This cell can no longer activate the pathway in neighbouring cells
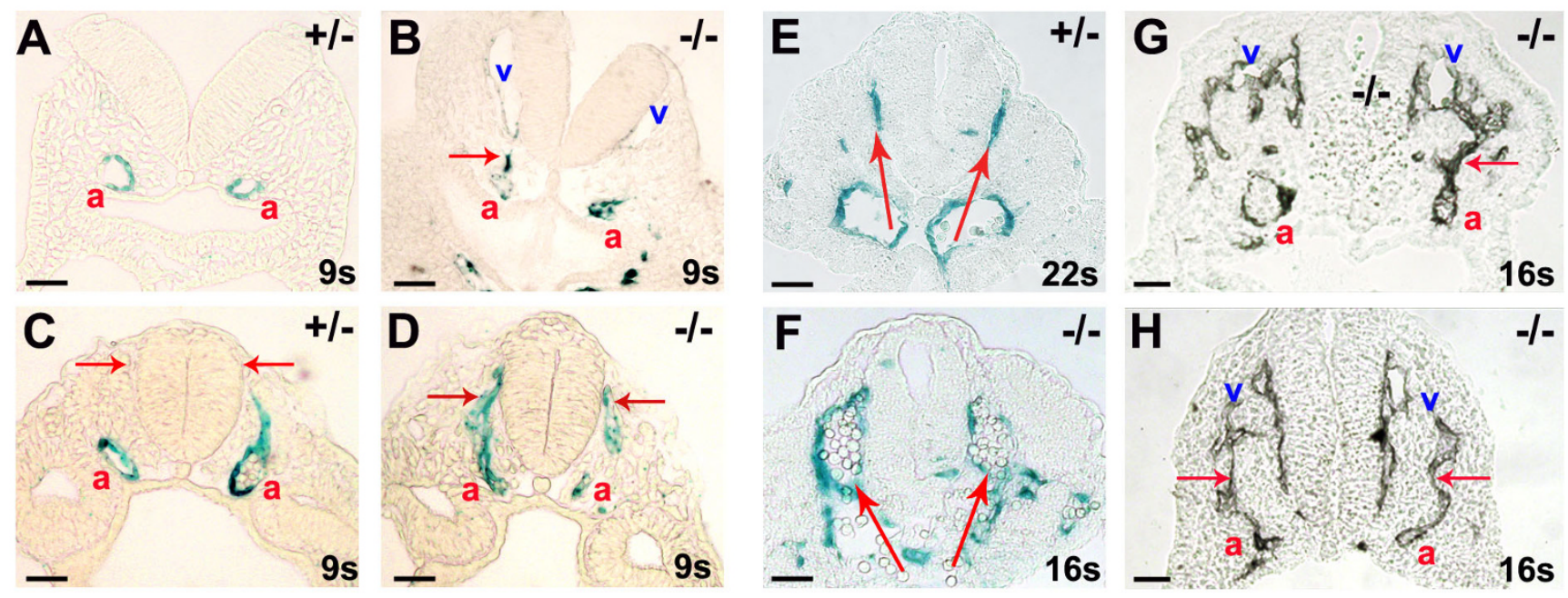

Figure 4

DII4-- endothelial cells migrate dorsally towards the neural tube, fusing with developing anterior cardinal veins. X-gal (A-F) and anti-PECAM-I $(G, H)$ staining of cryosections from the anterior $(A, B)$ and middle $(C-F)$ region of the Dll4 ${ }^{+/-}$ and D/l4-/- embryos with 8.5 (A-D) and $9.25 \mathrm{dpc}(\mathrm{E}-\mathrm{H})$. (A-D) D/l4-/- arterial endothelial cells migrate (arrows in B and D) towards the dorso-lateral region of the neural tube. In the anterior region of the DIll 4 null embryos, the aortic (a, $\beta$-galactosidase+) cells migrate towards the developing anterior cardinal vein (v), before the onset of circulation (B). (E, F) At later stages, in the middle region of the embryo, this dorsal migration leads to the delocalization of the dorsal aortae. The main circulation in the mutant embryos occurs through two vessels that localize laterally $(F)$ and not ventrally $(E)$ to the neural tube. $(\mathbf{G}, \mathbf{H})$ In the anterior region of the later-stage DII4-/ embryos the fusion (arrows) between the dorsal sprouting of the aortae (a) and the anterior cardinal veins (v) is evident. (Scale Bars: $50 \mu \mathrm{m}$ ). 
(that will in turn express more Delta) and therefore will acquire a different fate. This mechanism allows the differentiation between initially equivalent cells.

To understand how the Notch pathway regulates endothelial cell differentiation, we analysed endothelial cell expression of Notch1, Dll4 and Hey1 in early development of the arteries (dorsal aortae). In the initial stages of arterial development, Dll4 expression is patchy and not detected in all endothelial cells (data not shown). Some hours later, its expression is present in almost all endothelial cells of the dorsal aortae, although the level of expression differs from cell to cell. The expression of Notch1 and the effector Hey1 is also found in almost all arterial endothelial cells (Fig. 6A, B and 6C), which suggest that these genes can be expressed in the same cells. To explore this possibility, double in situ hybridization for Notch1 and Dll4 mRNA was carried out, showing that these genes are indeed expressed at high levels in the same cell (Fig. 6D, E and 6F). These results indicate that Notch activation in the arterial endothelium by Dll4 is likely to be inductive rather than inhibitory. Notch1 expression is also detected in the cardinal vein endothelium at early stages (Fig. 6D), but here it is lower than in the dorsal aortae, probably due to lack of Notch signalling induction by Dll4. In fact, Hey1 expression was not detected in the venous endothelium even at earlier stages of vein development (data not shown). In Dll4\% embryos, Notch1 expression was still detected in both veins and dorsal aortae, but in these embryos the expression levels seem to be equal between dorsal aortae and cardinal veins (Fig. 6G), suggesting that there is always a basal level of Notch1 expression that is independent of Dll4, and that Dll4 further induces Notch1 expression levels. Furthermore, there is a basal expression of Dll4 that is independent of Notch1 activation, since the Dll4-lacZ reporter gene is still expressed in Dll4 \% embryos in the absence of Hey1 expression (Fig. 6H, I).

\section{Discussion}

The initial steps of arterial morphogenesis require the migration of endothelial precursors and their assembly into lumenized vessels. Shortly after these vessels grow and branch accordingly to the cues provided by the surrounding tissues. Previous studies with Notch signalling defective zebrafish and mouse embryos showed the importance of the pathway in early arteriogenesis $[11,31]$. Here we show that the Notch ligand Dll4 regulates the arterial calibre and lumen by modulating the endothelial cell response to angiogenic factors like VEGF (Fig. 7).

The Dll4 gene is strongly expressed in the primordial arteries and heart of early embryos and its complete loss of function causes early and severe vascular defects [15]. As disruption of heart morphogenesis in several mutants is coincident with defects in vascular development, it is sometimes difficult to discern if failure of perfusion led to defective vascular development, or whether the vascular developmental defect is an independent event. Furthermore, in the early embryo it has previously been shown that blood flow can regulate the expression of some arterial specific genes, like Efnb2 [21], which is not detected in Dll4\% arterial endothelial cells [15]. To clarify if the early phenotype is caused by endothelial or cardiac/blood flow defects, Dll4\%-embryos were analysed before the onset of circulation. The results indicate that the arterial calibre reduction in these mutants is already clear at 8 ss, thus occurs earlier than the establishment of perfusion, and therefore cannot be caused by impaired haemodynamic forces but constitutes a primary vascular defect. This very early remodelling defect suggested a role of Dll4 in early vasculogenesis. However, the expression analysis of Notch1, Dll4 and Hey1 in early embryos revealed that only Notch1 can be expressed in angioblasts, which excludes the involvement of the Dll4 ligand in the initial endothelial cell differentiation from mesodermally derived cells.

Jagged1(Jag1) is another Notch ligand that is also expressed in the early embryo arterial endothelium. Total or endothelial specific Jag1 loss of function leads to embryo death at $10.5 \mathrm{dpc}[32,33]$, one day later than loss of Notch1 or Dll4. Endothelial Jag1 mutants show defects in the development of the arterial vascular smooth muscle without having a decrease of Notch signalling in endothelial cells [32]. Our results show that the Dll4\%-embryos suffer severe arterial calibre reduction before the existence of clearly differentiated smooth muscle cells $(\alpha-S M A+)$. Furthermore the mutant aortas are surrounded by neural crest derived smooth muscle cell progenitors (SM22 $\alpha+$ ), some of which are associated with the reduced mutant arterial endothelium. However these results do not exclude a role of Dll4 in arterial smooth muscle development at later stages of development.

The morphologic analysis of early (6-10 ss) dorsal aortae shows that the arterial calibre of the Dll4\%-embryos is much smaller than that of the wild-type, even though the number of endothelial cells is only slightly reduced. In addition, there is lack of a uniform laminin-rich basement membrane under the endothelial cells and a defective deposition of endothelial matrix proteins like collagenIV and specially fibronectin. Thus the abnormal organization of the mutant endothelial cells can be partially explained by defects in the formation of a proper endothelial basement membrane. These defects could be the result of either reduced production or active degradation of the basement membrane components. One of the most obvious consequences of this arterial cohesion defect is the extensive haemorrhaging observed in these mutant embryos upon the onset of blood flow. Interestingly, the 

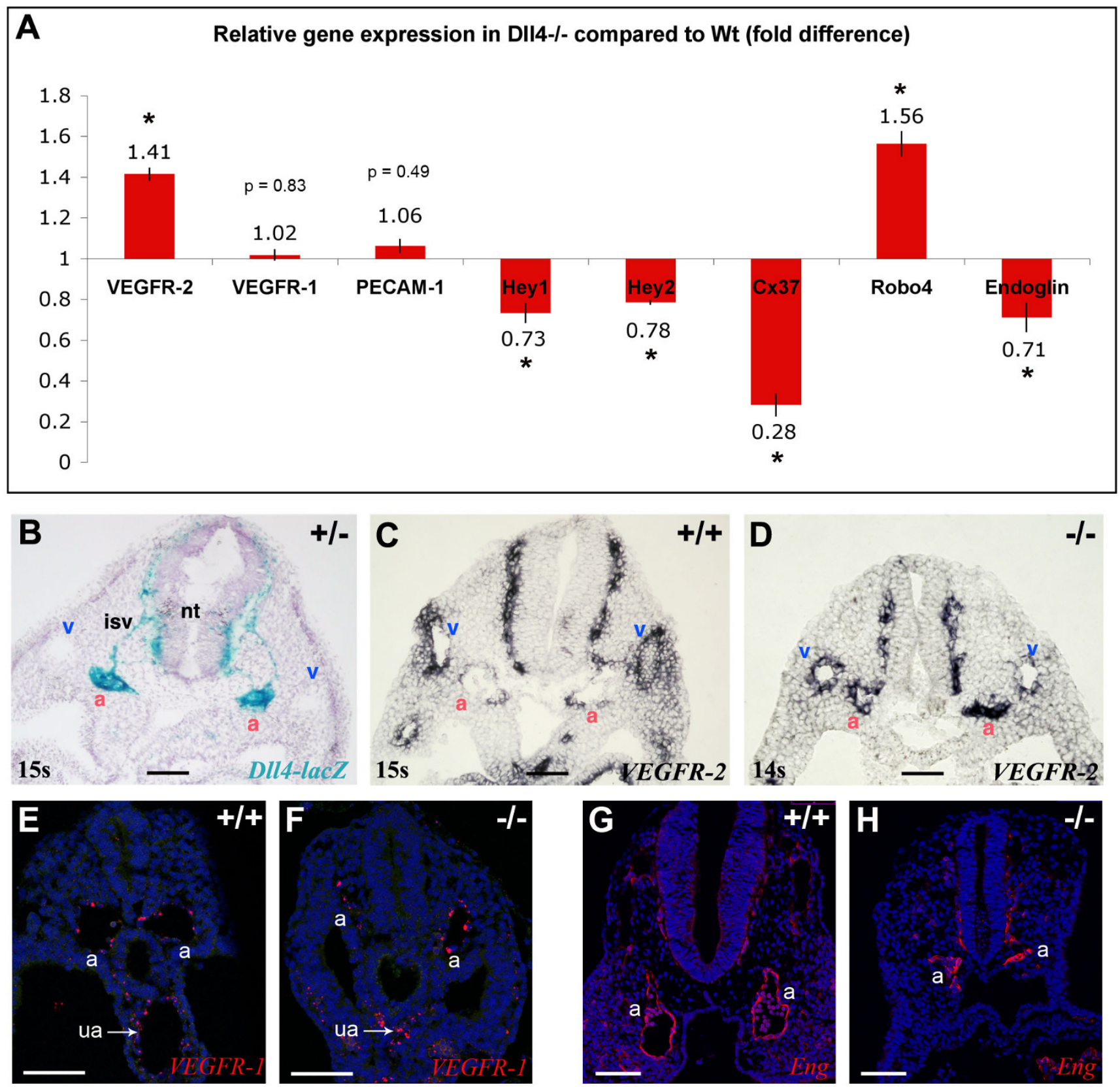

Figure 5

Higher expression of VEGFR-2 and Robo-4 but lower expression of Endoglin in DII4-/- embryos. (A) Relative quantitative gene expression in DI/4-/- embryos compared to $D / 14^{+/+}(n=4$ per group) show increased expression of VEGFR-2 and Robo-4 and lower expression of Endoglin in the DII4-/- mutants. Values were normalized to those of $\beta$-actin. (B-D) In situ hybridization on $9.0 \mathrm{dpc}$ embryos cryosections show upregulation of VEGFR-2 specifically in DII4-/- dorsal aortae (a). (B) In a thick section $(50 \mu \mathrm{m})$ of a DII4+/- embryo strong expression of Dll4 can be observed on the dorsal aortae and intersomitic vessels but no expression is detected on veins (v). (C) In a DIl/4+/ embryo VEGFR-2 is highly expressed in the veins and weakly expressed on the DII4 expressing dorsal aortae. (D) In the absence of the arterial DII4, VEGFR-2 is expressed at the same or at a higher level in the dorsal aortae compared to the anterior cardinal veins. (E, F) VEGFRI (Flt l) in situ hybridization (in red) showing similar endothelial expression levels between control and mutant aortae (a) and umbilical arteries (ua). DAPI in blue. $(\mathbf{G}, \mathbf{H})$ Imunostaining for Endoglin (CDI05) showing similar protein levels in endothelial cells of control and mutant embryos. Error bars represent st.dev. * indicates $p<0.05$. (Scale Bars: $100 \mu \mathrm{m}$ ). 

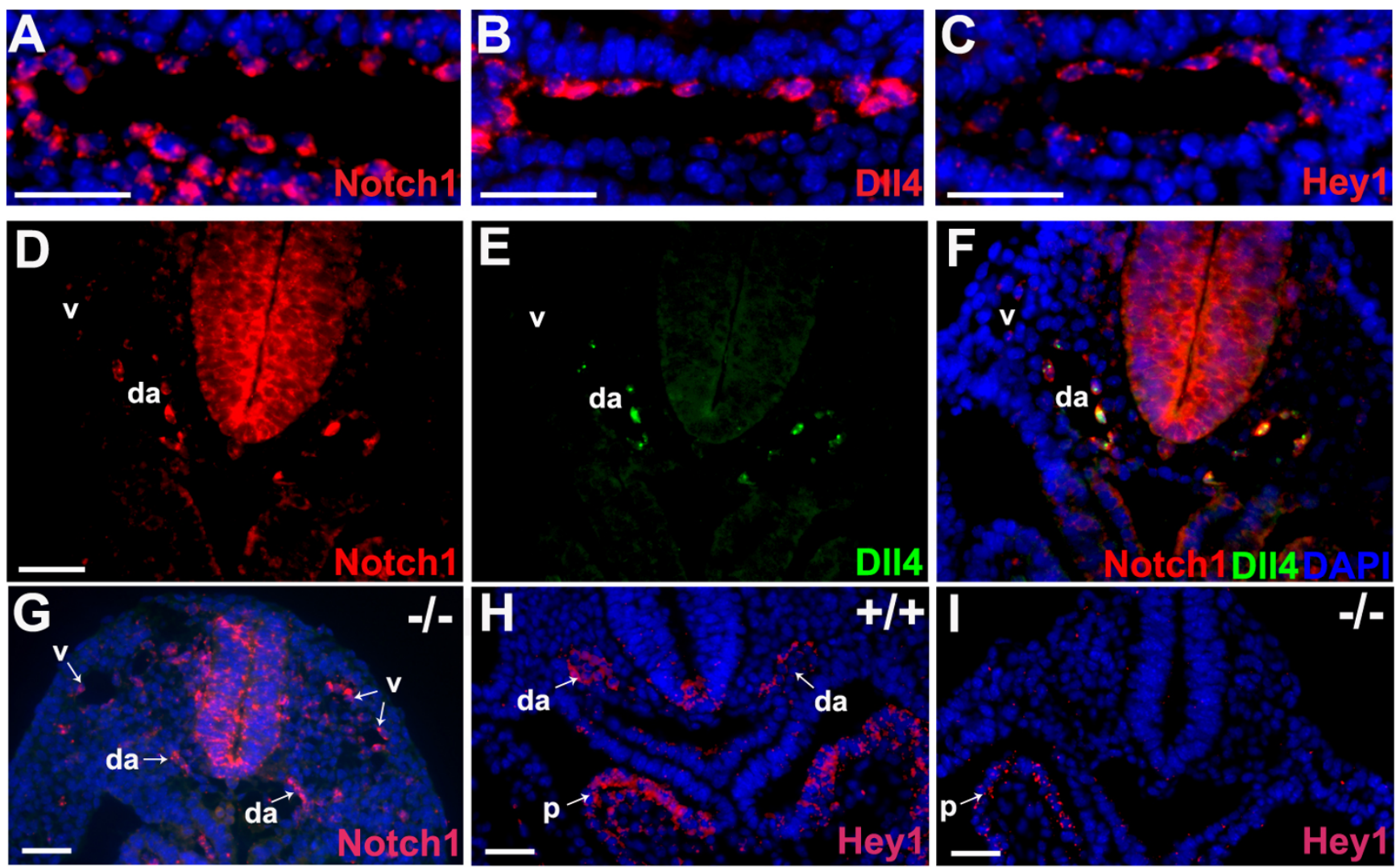

Figure 6

Notch I and DII4 are expressed at different levels in different cells but at high levels in the same cell of the developing arteries. (A-C) In situ hybridization on consecutive cryosections of $8.75 \mathrm{dpc}$ (I $2 \mathrm{ss}$ ) D/l4 ${ }^{+/+}$embryos showing that Notch I, DII4 and Heyl are expressed (red) in almost all aortic endothelial cells. (D-F) Double in situ hybridization for Notch I and DII4 reveals that these genes are expressed at high levels in the same cells. Note also that Notch I is weakly expressed on the anterior cardinal veins (v), where there is no expression of DII4. (G-I) In the DII4-/- embryos the Notch I receptor is still expressed on dorsal aortae (da) but there is no detectable endothelial expression of the effector Heyl (I), although its expression remains in the pericardium $(\mathrm{P})$. (Scale Bars: $50 \mu \mathrm{m})$.

defect observed in the basement membrane occurs in both the reduced and normal calibre regions of the Dll4-/dorsal aortae. This suggests that the arterial calibre reduction is not solely caused by a weaker and incomplete, and thus permissive, basement membrane, although this may influence the behaviour of endothelial cells in the presence of adequate angiogenic stimuli. In fact, the Dll4\%dorsal aortae present a normal calibre only in the presomitic region, where VEGF is produced exclusively by the endoderm. In the anterior and middle somitic regions of the embryo, VEGF is also produced by the neural tube and somites, forming a concentration gradient within the newly formed intersomitic spaces, and this difference in VEGF production may underlie the difference in arterial diameter between the anterior and posterior regions of the embryo. Besides VEGF, other neural tube derived factors like slits, semaphorins and netrins can attract endothelial cells and be responsible for the correct alignment of the dorsal aortae, since ablation of VEGF in the peripheral nerves of the skin does not impair the co-alignment between arteries and nerves [34].

The Dll4\%- aortic endothelial cells are likely to respond more than their wild-type counterparts to the neural tube or somite secreted factors, because they migrate earlier and in higher numbers. Alternatively these mutant endothelial cells could be less susceptible to the repulsive factors produced in neural tube or somites. This is unlikely, as vascular invasion of somites or neural tube was not observed. Besides increased migration, the mutant arterial endothelial cells have increased proliferation to nearly twice that of wild-type endothelial cells, which further confirms the higher responsiveness of these cells to local angiogenic factors. These results indicate that the observed smaller arterial calibre and reduced number of endothelial cells is caused by an active outward cell 

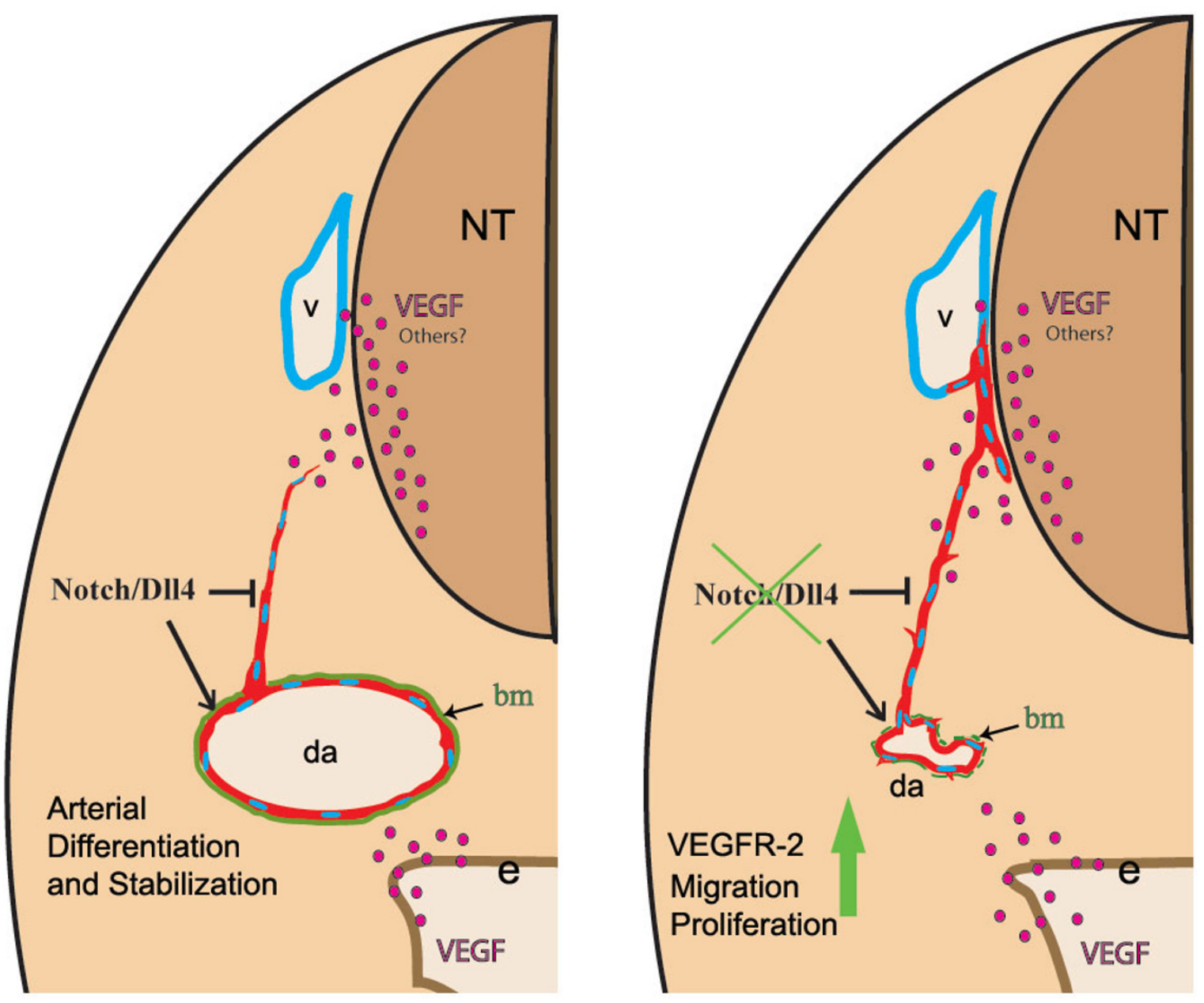

\section{Figure 7}

Regulation of arterial calibre and endothelial cell migration by Dll4. Model illustrating the difference in the behaviour of endothelial cells in the presence or absence of Notch signalling mediated by the Dll4 ligand in the early embryo arterial endothelium. The loss of Notch signalling leads to downregulation of arterial specific genes and upregulation of VEGFR-2 which may increase migration and proliferation of endothelial cells. The dorsal aortae (da) endothelial cells migrate towards the lateral region of the neural tube (nt) or pre-formed veins $(\mathrm{v})$ with which they fuse. In the DII4 $4^{+/+}$embryos Notch signalling induces arterial endothelial cell differentiation and stabilization, as well as promoting the formation of a consistent basement membrane (bm).

migration that overcomes the increase in arterial cell proliferation. Previous in vitro studies with human endothelial cells also demonstrated that Notch signalling activation decreases endothelial cell proliferation [35,36]. Our in vivo findings are consistent with these observations and suggest that Dll4 induced Notch signalling can be a physiological inhibitor of endothelial cell proliferation, allowing cells to differentiate and form an optimal vascular lumen.

The role of Notch signalling in early angiogenesis appears therefore to be fundamentally different than that described in Notch regulation of early neurogenesis, in which a pool of non-committed neuroblasts is induced to proliferate and prevented from differentiating by Notch controlled lateral inhibition $[37,38]$. The in situ hybridization data in the current study suggests that arterial endothelial Notch signalling is inductive rather than inhibitory because the Notch1 receptor and the Dll4 ligand are expressed at high levels in the same cell and almost in all aortic endothelial cells. The in vivo activation of Notch signalling in adult mouse arteries leads to increased expression of the ligand Dll4, Notch receptors, and downstream effectors such as bHLH transcription fac- 
tor Hey1, which supports the possibility that Notch signalling induces a positive loop in endothelial cells resulting in induction of Notch receptor and its cognate ligand [39]. Furthermore there is a basal level of Notch1 and Dll4 expression in arterial endothelial cells that is independent of Notch-Dll4 signalling, since there is expression of both the Dll4-lacZ reporter and Notch1 in the Dll4\% mutants.

The RT-PCR and in situ hybridization results obtained are consistent with the observed mutant endothelial cell behaviour. The Dll4\% arterial endothelial cells express more VEGFR-2 which is required for VEGF mediated endothelial cell migration and proliferation [40]. This direct relationship between VEGF signalling and the Notch pathway was previously suggested by in vitro studies with HUVECs where Notch activation, through the upregulation of Dll4, reduces the expression of VEGFR-2 and Nrp-1 $[41,42]$. The receptor Robo-4 is also upregulated in the Dll4 \%-embryos. At the stages analysed it is expressed throughout the endothelial network and, like VEGFR-2, it is further induced at sites of active angiogenesis. In vivo knockdown of Robo-4 in zebrafish embryos suppresses the formation of intersomitic vessels due to inhibition of endothelial cell sprouting and migration, seen by time-lapse analysis [23], which is the opposite to the phenotype observed in Dll4\%- mouse embryos. Robo4 also participates in attraction-guidance through RhoGTPases in vascular development, as Robo-4 gain of function experiments in vitro showed activation of Cdc42 and Rac1 Rho-GTPases [26]. Therefore Robo-4 may be one of the mediators of the increased migration of $\mathrm{Dll4} \%$ endothelial cells in response to its ligand Slit produced by the somites and the neural tube. Interestingly, Robo-4 levels decline in the Dll4 expressing dorsal aortae after 9.0 $\mathrm{dpc}[24]$ and in the mouse retina Robo-4 is not expressed in the tip cells known to highly express Dll4 [28]. However, deletion of Robo-4 in the mouse is not lethal and developmental angiogenesis occurs normally [28], suggesting that its function might be compensated by other genes. Nonetheless its loss of function enhances postnatal induced pathologic angiogenesis and endothelial permeability. This inhibition is thought to depend on Slit2-Robo4 suppression of VEGF165-Src induced endothelial migration and tube formation but not proliferation [28]. Although controversial these results suggest that Robo4 could act differently during development and pathological angiogenesis. We also found a significant reduction in the expression of the TGF- $\beta 1$ co-receptor endoglin. Eng-/- mutant embryos die around 10.5 dpc due to several cardiovascular defects that also include abnormal arterio-venous fusions, and this phenotype is independent of loss of Efnb2 expression [30,43]. Furthermore, in vitro studies show that Eng-/- endothelial cells have increased proliferation [29].
The vessel response to angiogenic factors must be tightly regulated to ensure a balance between the formation of new sprouts and the remodelling of previously formed vessels. Such regulation allows the formation of a hierarchical system of vessels with critical contribution from the Notch-Dll4 pathway, which modulates VEGF signalling in endothelial cells. An important example of this role has been recently reported in relation to the vascularisation of the retina in newborn mice [44-46].

We observed migration of Dll4 \%- aortic endothelial cells towards the developing anterior cardinal veins in the dorso-lateral region of the neural tube (Fig. 7). This migration and delocalization of the "arterial" Dll4 \%-endothelial cells to the assembly region of the primordial veins may be related to faulty differentiation [13,15,31,47] and increased responsiveness to the angiogenic factors.

VEGF induces expression of Dll4 [48] which in turn, by activating the Notch pathway, reduces endothelial cell sensitivity and responsiveness to VEGF. We thus suggest that the Notch pathway could constitute a negative feedback mechanism to ensure that the formation and extension of new arterial vessel branches occurs only after the growth and stabilization of the preceding main arterial vessels. Without Notch signalling the arterial endothelial cells proliferate and migrate in an uncontrolled manner, resulting in the formation of a vasculature that is not efficient in blood distribution due to exaggerated branching and extension of the preformed vessels. A number of recent reports indicate that this is also the case during tumour neoangiogenesis, with loss of Notch activation by Dll4 resulting in an inefficient vascular bed due to a disproportionate increase in vessel branching [49-51].

\section{Conclusion}

Many of the currently used anti- or pro-angiogenic therapies were designed after important findings concerning early mouse embryo vascular development. The present data shows that activation of the Notch pathway by the ligand Dll4 can regulate several different key steps in arteriogenesis through interaction with other important endothelial signalling mechanisms. The understanding of these interactions between different signalling pathways offers alternatives for future therapeutic intervention.

\section{Authors' contributions}

$\mathrm{RB}$ participated in the design of the studies, acquisition of the data, preparation of the figures and writing of the manuscript. AT participated in the experiments discussion, improved some techniques and revised the manuscript. $\mathrm{MH}$ carried out the first experiments which originated this research work and revised the manuscript. DH, LLC, JR and PSG participated in the discussion of the experiments and revision of the manuscript. AD con- 
ceived the study, participated in its design and coordination and helped write the manuscript. All authors read and approved the final manuscript.

\section{Acknowledgements}

We thank Dr. Susana Rocha for helpful discussions and technical advice and Eng. Patrícia Diniz for expert technical assistance. DH is supported by the Portuguese Science and Technology Foundation (FCT; grant POCTI/BCI/ 4883). JR is supported by a grant from the National Cancer Institute of Canada with funds from the Terry Fox Foundation. PSG is supported by the National Cancer Institute (USA). AD is supported by FCT (grants POCTI/ CVT/48766 and POCTI/CVT/560I5). RB and AT are recipients of a PhD studentship from FCT.

\section{References}

I. Risau W: Mechanisms of angiogenesis. Nature 1997, 386:67I-4.

2. Carmeliet P, Ferreira V, Breier G, Pollefeyt S, Kieckens L, Gertsenstein M, Fahrig M, Vandenhoeck A, Harpal K, Eberhardt C, et al.: Abnormal blood vessel development and lethality in embryos lacking a single VEGF allele. Nature 1996, 380:435-9.

3. Shalaby F, Rossant J, Yamaguchi TP, Gertsenstein M, Wu XF, Breitman ML, Schuh AC: Failure of blood-island formation and vasculogenesis in Flk-I-deficient mice. Nature 1995, 376:62-6.

4. Fong GH, Rossant J, Gertsenstein M, Breitman ML: Role of the FItI receptor tyrosine kinase in regulating the assembly of vascular endothelium. Nature 1995, 376:66-70.

5. Fong GH, Zhang L, Bryce DM, Peng J: Increased hemangioblast commitment, not vascular disorganization, is the primary defect in fit-I knock-out mice. Development 1999, | 26:3015-25.

6. Hiratsuka S, Minowa O, Kuno J, Noda T, Shibuya M: FIt-I lacking the tyrosine kinase domain is sufficient for normal development and angiogenesis in mice. Proc Natl Acad Sci USA 1998 , 95:9349-54.

7. Park JE, Chen HH, Winer J, Houck KA, Ferrara N: Placenta growth factor. Potentiation of vascular endothelial growth factor bioactivity, in vitro and in vivo, and high affinity binding to Flt-I but not to Flk-I/KDR. I Biol Chem 1994, 269:25646-54

8. Kearney JB, Kappas NC, Ellerstrom C, DiPaola FW, Bautch VL: The VEGF receptor flt-I (VEGFR-I) is a positive modulator of vascular sprout formation and branching morphogenesis. Blood 2004, I 03:4527-35.

9. Eichmann A, Le Noble F, Autiero M, Carmeliet P: Guidance of vascular and neural network formation. Curr Opin Neurobiol 2005 , 15:108-15.

10. Rossant J, Howard L: Signaling pathways in vascular development. Annu Rev Cell Dev Biol 2002, I 8:54I-73.

II. Krebs LT, Xue Y, Norton CR, Shutter JR, Maguire M, Sundberg JP, Gallahan D, Closson V, Kitajewski J, Callahan R, et al: Notch signaling is essential for vascular morphogenesis in mice. Genes Dev 2000, 14:1343-52.

12. Shutter JR, Scully S, Fan W, Richards WG, Kitajewski J, Deblandre GA, Kintner CR, Stark KL: DII4, a novel Notch ligand expressed in arterial endothelium. Genes Dev 2000, I 4:1313-8.

13. Krebs LT, Shutter JR, Tanigaki K, Honjo T, Stark KL, Gridley T: Haploinsufficient lethality and formation of arteriovenous malformations in Notch pathway mutants. Genes Dev 2004 18:2469-73.

14. Gale NW, Dominguez MG, Noguera I, Pan L, Hughes V, Valenzuela DM, Murphy AJ, Adams NC, Lin HC, Holash J, et al.: Haploinsufficiency of delta-like 4 ligand results inembryonic lethality due to major defects in arterial and vascular development. Proc Natl Acad Sci USA 2004, 10 I: 15949-54.

15. Duarte A, Hirashima M, Benedito R, Trindade A, Diniz P, Bekman E, Costa L, Henrique D, Rossant J: Dosage-sensitive requirement for mouse Dll4 in artery development. Genes Dev 2004 18:2474-8.

16. Hogan B, Beddington R, Constantini F, Lacy E: Manipulating the mouse embryo. A laboratory manual. Second edition. Cold Spring Harbor Laboratory Press; 1994.

17. Yamaguchi TP, Dumont DJ, Conlon RA, Breitman ML, Rossant J: flk$\mathrm{I}$, an flt-related receptor tyrosine kinase is an early marker for endothelial cell precursors. Development 1993, I I 8:489-98.
18. Nakagawa O, Nakagawa M, Richardson JA, Olson EN, Srivastava D HRTI, HRT2, and HRT3: a new subclass of bHLH transcription factors marking specific cardiac, somitic, and pharyngeal arch segments. Dev Biol 1999, 216:72-84.

19. Breier G, Albrecht U, Sterrer S, Risau W: Expression of vascular endothelial growth factor during embryonic angiogenesis and endothelial cell differentiation. Development 1992, I 1 4:521-32

20. Myat A, Henrique D, Ish-Horowicz D, Lewis J: A chick homologue of Serrate and its relationship with Notch and Delta homologues during central neurogenesis. Dev Biol 1996, 174:233-47.

2I. le Noble F, Moyon D, Pardanaud L, Yuan L, Djonov V, Matthijsen R, Breant C, Fleury V, Eichmann A: Flow regulates arterial-venous differentiation in the chick embryo yolk sac. Development 2004 |3 |:36|-75

22. Drake CJ, Fleming PA: Vasculogenesis in the day $\mathbf{6 . 5}$ to 9.5 mouse embryo. Blood 2000, 95:167I-9.

23. Bedell VM, Yeo SY, Park KW, Chung J, Seth P, Shivalingappa V, Zhao J, Obara T, Sukhatme VP, Drummond IA, et al.: roundabout4 is essential for angiogenesis in vivo. Proc Natl Acad Sci USA 2005, 102:6373-8

24. Park KW, Morrison CM, Sorensen LK, Jones CA, Rao Y, Chien CB Wu JY, Urness LD, Li DY: Robo4 is a vascular-specific receptor that inhibits endothelial migration. Dev Biol 2003, 26 I:25I-67.

25. Jonker L, Arthur HM: Endoglin expression in early development is associated with vasculogenesis and angiogenesis. Mech Dev 2002, I I 0:193-6.

26. Kaur S, Castellone MD, Bedell VM, Konar M, Gutkind JS, Ramchandran R: Robo4 signaling in endothelial cells implies attraction guidance mechanisms. J Biol Chem 2006, 28 I: I I347-56.

27. Ferrara N, Gerber HP, LeCouter J: The biology of VEGF and its receptors. Nat Med 2003, 9:669-76.

28. Jones CA, London NR, Chen H, Park KW, Sauvaget D, Stockton RA, Wythe JD, Suh W, Larrieu-Lahargue F, Mukouyama YS, et al.: Robo4 stabilizes the vascular network by inhibiting pathologic angiogenesis and endothelial hyperpermeability. Nat Med 2008, 14(4):448-453.

29. Pece-Barbara N, Vera S, Kathirkamathamby K, Liebner S, Di Guglielmo GM, Dejana E, Wrana JL, Letarte M: Endoglin null endothelial cells proliferate faster and are more responsive to transforming growth factor betal with higher affinity receptors and an activated Alk I pathway. I Biol Chem 2005, 280:27800-8.

30. Li DY, Sorensen LK, Brooke BS, Urness LD, Davis EC, Taylor DG, Boak BB, Wendel DP: Defective angiogenesis in mice lacking endoglin. Science 1999, 284:1534-7.

31. Lawson ND, Scheer N, Pham VN, Kim CH, Chitnis AB, CamposOrtega JA, Weinstein BM: Notch signaling is required for arterial-venous differentiation during embryonic vascular development. Development 200I, I 28:3675-83.

32. High FA, Lu MM, Pear WS, Loomes KM, Kaestner KH, Epstein JA: Endothelial expression of the Notch ligand Jagged I is required for vascular smooth muscle development. Proc Nat Acad Sci USA 2008, 105: 1955-9.

33. Xue $Y$, Gao X, Lindsell CE, Norton CR, Chang B, Hicks C, GendronMaguire M, Rand EB, Weinmaster G, Gridley T: Embryonic lethality and vascular defects in mice lacking the Notch ligand Jagged I. Hum Mol Genet 1999, 8:723-30.

34. Mukouyama YS, Gerber HP, Ferrara N, Gu C, Anderson DJ: Peripheral nerve-derived VEGF promotes arterial differentiation via neuropilin I-mediated positive feedback. Development 2005, I 32:941-952.

35. Sainson RC, Aoto J, Nakatsu MN, Holderfield M, Conn E, Koller E, Hughes CC: Cell-autonomous notch signaling regulates endothelial cell branching and proliferation during vascular tubulogenesis. FASEB J 2005, 19:1027-1029.

36. Liu ZJ, Xiao M, Balint K, Soma A, Pinnix CC Capobianco AJ, Velazquez OC, Herlyn M: Inhibition of endothelial cell proliferation by Notch I signaling is mediated by repressing MAPK and PI3K/Akt pathways and requires MAMLI. Faseb / 2006 20:1009-II.

37. Lewis J: Neurogenic genes and vertebrate neurogenesis. Curr Opin Neurobiol 1996, 6:3-10.

38. Henrique D, Hirsinger E, Adam J, Le Roux I, Pourquié O, Ish-Horowicz D, Lewis J: Maintenance of neuroepithelial progenitor cells 
by Delta-Notch signalling in the embryonic chick retina. Curr Biol 1997, 13:661-670

39. Carlson TR, Yan Y, Wu X, Lam MT, Tang GL, Beverly LJ, Messina LM, Capobianco AJ, Werb Z, Wang R: Endothelial expression of constitutively active Notch4 elicits reversible arteriovenous malformations in adult mice. Proc Natl Acad Sci USA 2005, 102:9884-9.

40. Ferrara N, Kerbel RS: Angiogenesis as a therapeutic target. Nature 2005, 438:967-74.

41. Williams CK, Li JL, Murga M, Harris AL, Tosato G: Upregulation of the Notch ligand Delta-like 4 inhibits VEGF-induced endothelial cell function. Blood 2005, 107(3):93I-939.

42. Taylor KL, Henderson AM, Hughes CC: Notch activation during endothelial cell network formation in vitro targets the basic HLH transcription factor HESR-I and downregulates VEGFR-2/KDR expression. Microvasc Res 2002, 64:372-83.

43. Arthur HM, Ure J, Smith AJ, Renforth G, Wilson DI, Torsney E, Charlton R, Parums DV, Jowett T, Marchuk DA, et al.: Endoglin, an ancillary TGFbeta receptor, is required for extraembryonic angiogenesis and plays a key role in heart development. Dev Biol 2000, 217:42-53.

44. Suchting S, Freitas C, le Noble F, Benedito R, Breant C, Duarte A, Eichmann A: The Notch ligand Delta-like 4 negatively regulates endothelial tip cell formation and vessel branching. Proc Natl Acad Sci USA 2007.

45. Lobov IB, Renard RA, Papadopoulos N, Gale NW, Thurston G, Yancopoulos GD, Wiegand SJ: Delta-like ligand 4 (DII4) is induced by VEGF as a negative regulator of angiogenic sprouting. Proc Natl Acad Sci USA 2007.

46. Hellstrom M, Phng LK, Hofmann JJ, Wallgard E, Coultas L, Lindblom P, Alva J, Nilsson AK, Karlsson L, Gaiano N, et al.: DIl4 signalling through Notch I regulates formation of tip cells during angiogenesis. Nature 2007, 445(7/29):776-780.

47. Lawson ND, Vogel AM, Weinstein BM: sonic hedgehog and vascular endothelial growth factor act upstream of the Notch pathway during arterial endothelial differentiation. Dev Cell 2002, 3: 127-36.

48. Liu ZJ, Shirakawa T, Li Y, Soma A, Oka M, Dotto GP, Fairman RM, Velazquez OC, Herlyn M: Regulation of Notch I and DIl4 by vascular endothelial growth factor in arterial endothelial cells: implications for modulating arteriogenesis and angiogenesis. Mol Cell Biol 2003, 23: I4-25.

49. Scehnet JS, Jiang W, Kumar SR, Krasnoperov V, Trindade A, Benedito R, Djokovic D, Borges C, Ley EJ, A Duarte, et al.: Inhibition of DII4 mediated signaling induces proliferation of immature vessels and results in poor tissue perfusion. Blood 2007.

50. Ridgway J, Zhang G, Wu Y, Stawicki S, Liang WC, Chanthery Y, Kowalski J, Watts RJ, Callahan C, Kasman I, et al.: Inhibition of DII4 signalling inhibits tumour growth by deregulating angiogenesis. Nature 2006, 444: 1083-7.

5I. Noguera-Troise I, Daly C, Papadopoulos NJ, Coetzee S, Boland P, Gale NW, Lin HC, Yancopoulos GD, Thurston G: Blockade of DII4 inhibits tumour growth by promoting non-productive angiogenesis. Nature 2006, 444:1032-7.
Publish with Bio Med Central and every scientist can read your work free of charge

"BioMed Central will be the most significant development for disseminating the results of biomedical research in our lifetime. "

Sir Paul Nurse, Cancer Research UK

Your research papers will be:

- available free of charge to the entire biomedical community

- peer reviewed and published immediately upon acceptance

- cited in PubMed and archived on PubMed Central

- yours - you keep the copyright
BioMedcentral 